\title{
Tendencia descentralizadora y derecho a la educación
}

ฐั้

Mt 14, He. IH,

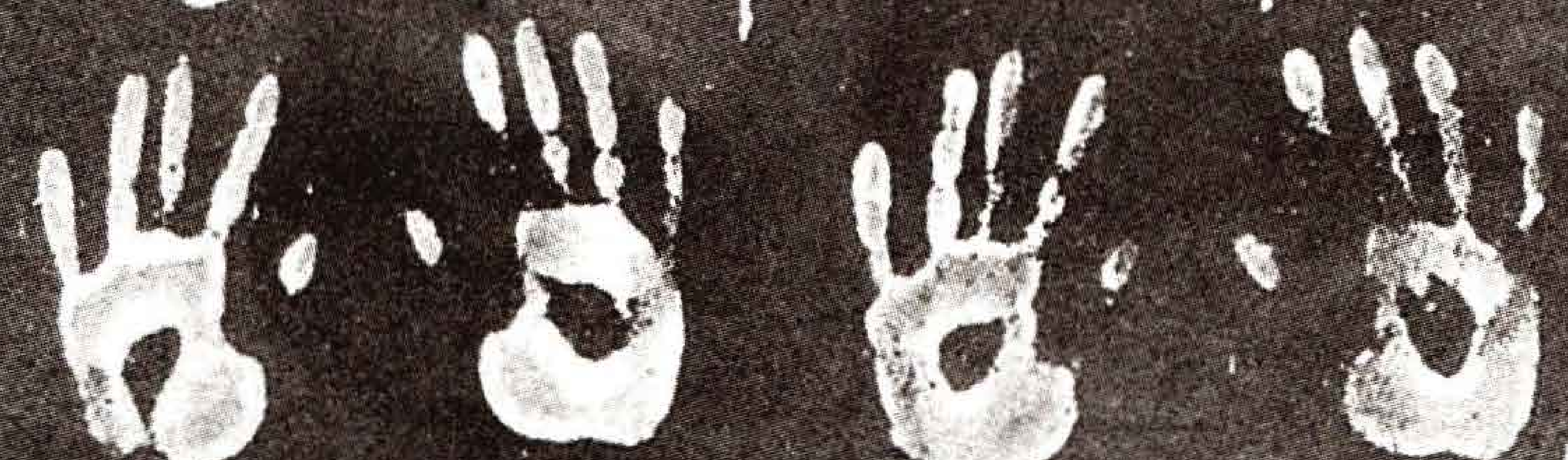

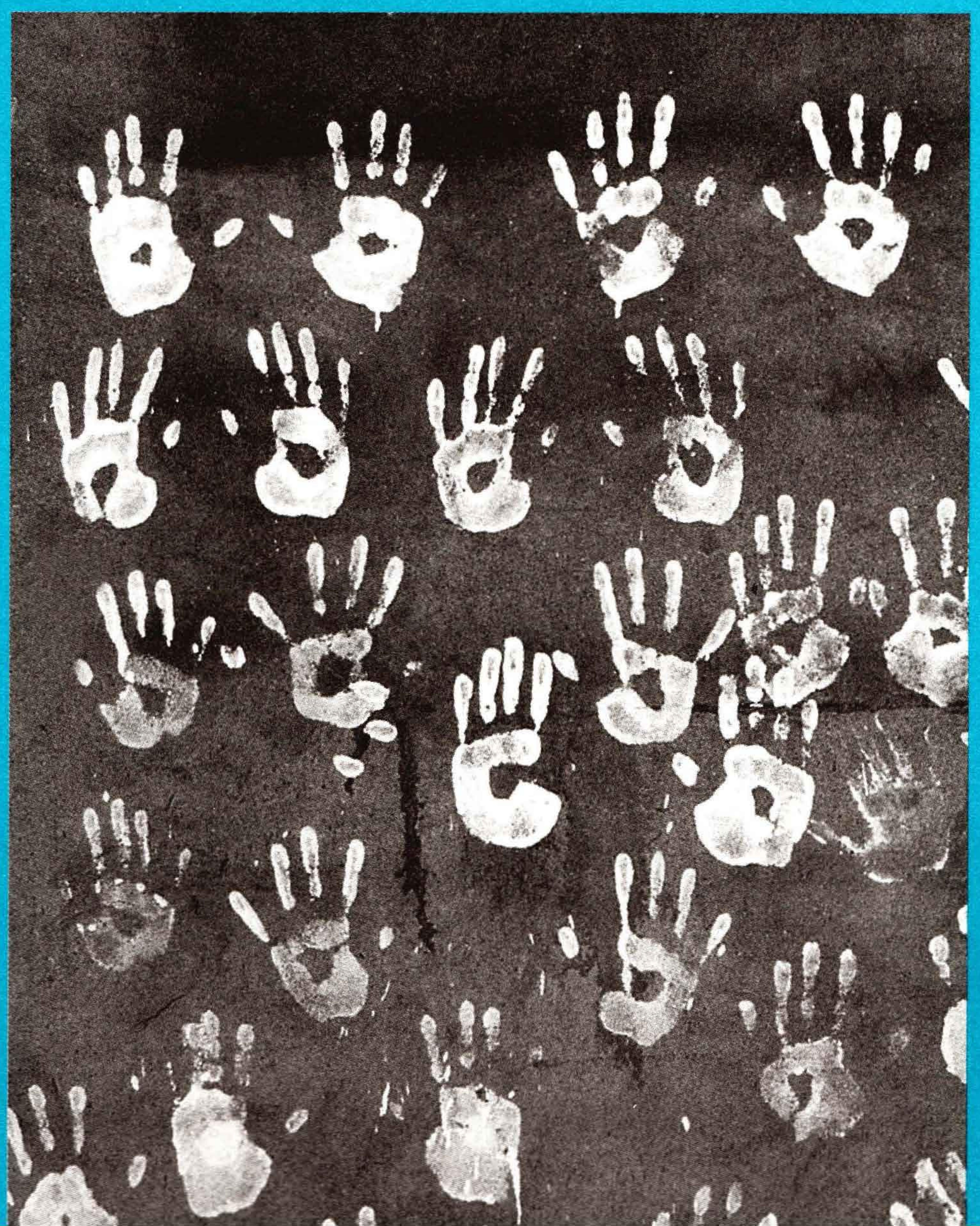




\section{Manuel Iguiñiz Echeverría}

Magister en Sociología, Universidad de París VIII, Vincennes, Francia. Licenciado en Sociología, Universidad Nacional Mayor de San Marcos. Ministerio de Educación, Asesor de la Alta Dirección, Viceministro de Gestión Institucional. Presidente de la Asociación Nacional de Centros de Promoción y Desarrollo, ANC; Vicepresidente del Consejo de Educación de Adultos para América Latina -CEAAL-. Actualmente es Presidente de Foro Educativo y Miembro de TAREA, Catedrático de la Maestría de Sociología de la Educación, Facultad de Ciencias Sociales de la Universidad Nacional Mayor de San Marcos (Lima, Perú). Algunas publicaciones: Dos miradas a la Gestión de la Escuela Pública (1998), en coautoría con Dueñas, Claudia. Materiales para pensar la descentralización educativa, en coautoría con Del Castillo, Daniel (ED. TAREA, Lima, 1995).

\section{Resumen}

Este artículo analiza las tendencias descentralizadoras en América Latina desde el punto de vista de lo que las políticas internacionales significan tanto para los gobiernos nacionales como locales. Destaca la importancia de las decisiones políticas de los ministerios de educación y hace un balance de lo que han significado estas tendencias para algunos países del área. Se apoya en documentos de la Unesco, y señala que para desarrollar una discusión de fondo sobre las cuestiones actuales del aprendizaje y la enseñanza, también hay que incluir el hecho de que la mayor iniciativa en cuestiones curriculares y programas nacionales de mejoramiento han estado en muchos casos ligados al financiamiento de la banca internacional.

\section{Palabras clave}

Descentralización, centralización, gobierno, educación, equidad, escuela, participación, políticas.

\section{Abstract}

This article analyzes the decentralization tendencies in Latin America from the point of view of the implications of international policies for both national and local governments. It underlines the importance of political decisions of the Education Ministries and evaluates the tendencies of some of these decisions in the region. It is supported on UNESCO documents and it points out that to develop a complete discussion about the questions of learning and teaching, it is important to take into account that most curriculum reforms and improvement plans have been related to international financing through multilateral banking.

\section{Key words}

Decentralization, centralization, government, education equiity, school, participation, policies. 


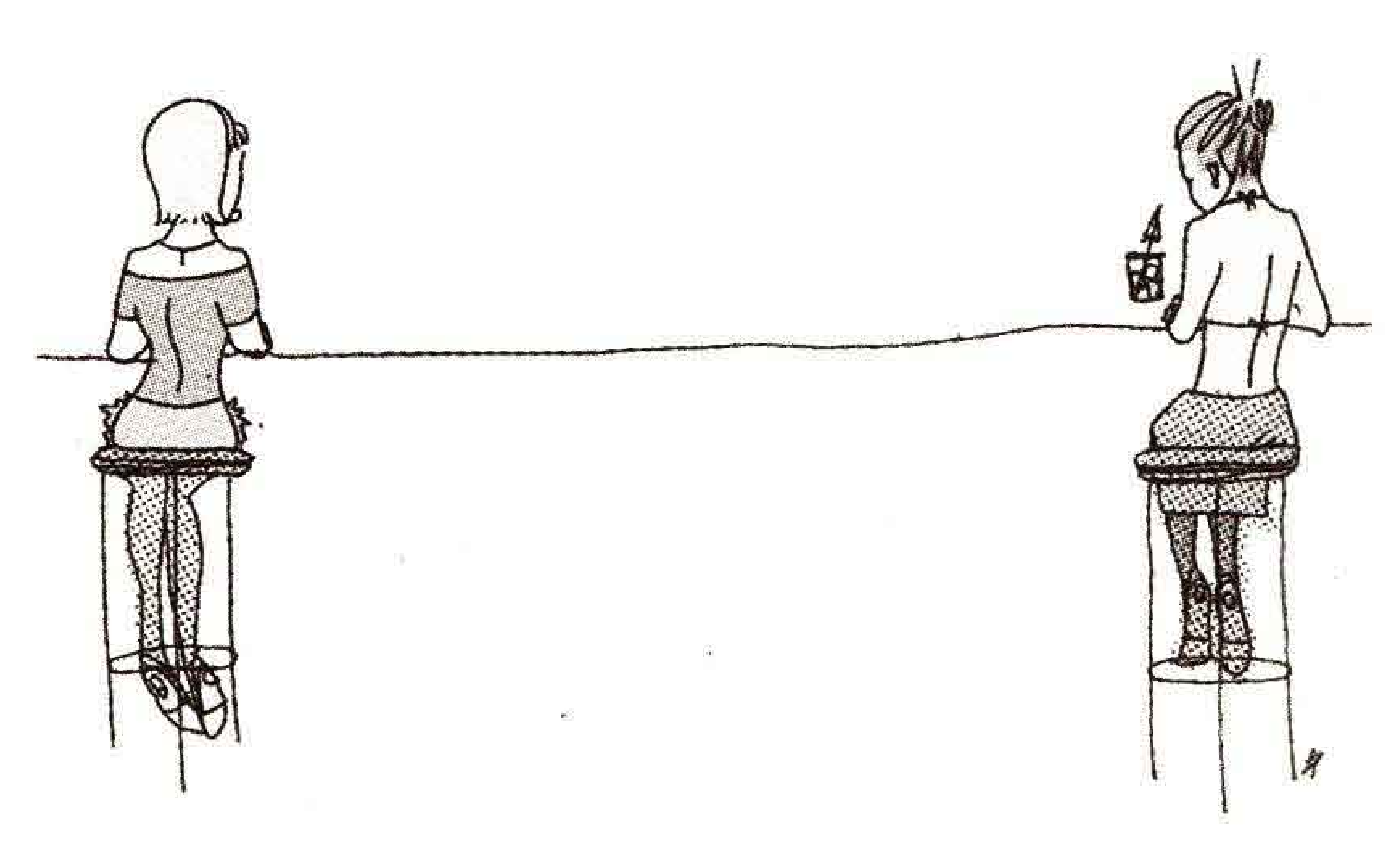

\section{La complejidad política de la descentralización ${ }^{1}$}

$\square$ 1 carácter político de la redistribución del poder, inherente a la descentralización del Estado tiene -cuestión extraña- reconocimiento casi unánime. El asunto de la descentralización es omnipresente en la política y es tema obligado aun para quienes lo eluden. Cuando se discute sobre la descentralización del Estado, son frecuentes los argumentos a favor y los "deber ser", como si se tratara de un proceso simple. Frente a la descentralización educativa ocurre algo parecido. Silvia Senén afirma que en las últimas décadas ésta ha pasado de ser un asunto controversial a obtener una aceptación casi general en cuanto a la mejora de la gestión, “... pero con más reflexión sobre distintas variantes”. (1994, 24).

En cuanto a las variantes descentralizadoras, algunas resultan complementarias y otras entran en tensión. En Perú, por ejemplo, el proyecto de "descentralización con privatización" de Alberto Fujimori, desarrollado entre 1992 y 1993, generó confrontación la posición de muchas instituciones del país. Hubo un segundo anuncio de descentralización administrativa a finales de su segundo gobierno, claramente orientado hacia la

\footnotetext{
1 Artículo basado en la ponencia presentada en el 'Taller de alfabetización económica en financiación y educación', presentada por la Campaña Latinoamericana por el Derecho a la Educación. Bogotá, noviembre de 2005.
}

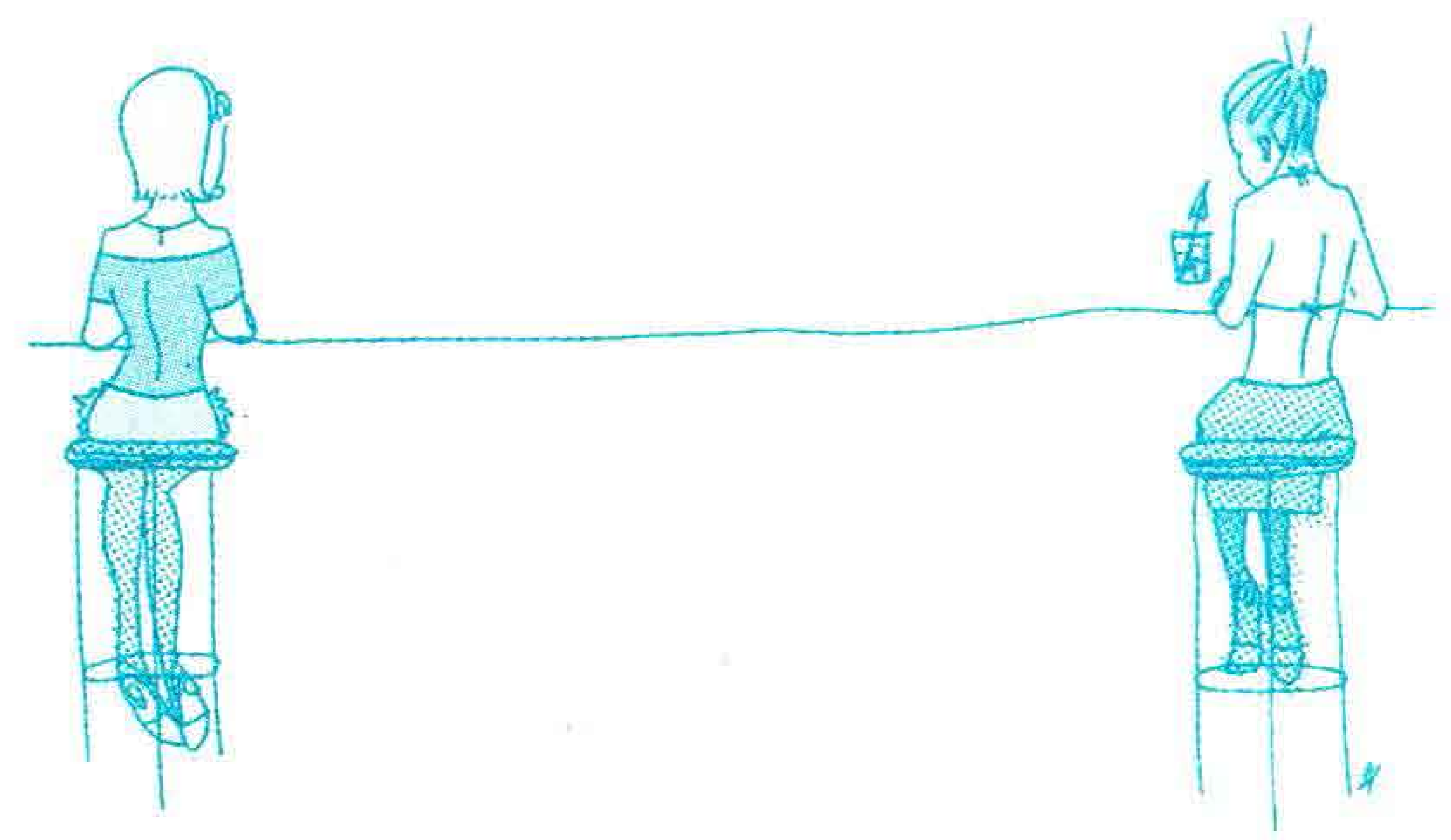

búsqueda de una "legitimación compensatoria" del Estado y del gobierno dictatorial.

A la descentralización política, y específicamente a la educativa, se la sustenta generalmente con un discurso legitimador muy amplio. Discurso que, como lo indica L. Sime (1995), se nutre de un proceso histórico, dialoga con otros discursos y busca legitimarse: el discurso de la descentralización educativa se presenta como "... creible, imprescindible y viable" (L. Sime, 1995, 168). El Gráfico 1 es una versión basada en la de L. Sime sobre la educación en derechos humanos.

Se plantean muchos argumentos convergentes, razón por la cual es importante recogerlos, discutirlos y evitar su mitificación, como lo señala Ricardo Cuenca $(2005,2)$, para quien cinco hay razones que suelen sustentar la validez de la descentralización:

- Es sinónimo de desarrollo, calidad y equidad.

- Permite conocer mejor los problemas.

- Redistribuye poder.

- Favorece la identidad regional y local.

- Optimiza los recursos económicos.

Ricardo Hevia señala la complejidad de motivos y racionalidades que se entrecruzan, como producto de los diferentes intereses que llevan a los actores a realizar determinadas transacciones. En un 
Gráfico 1

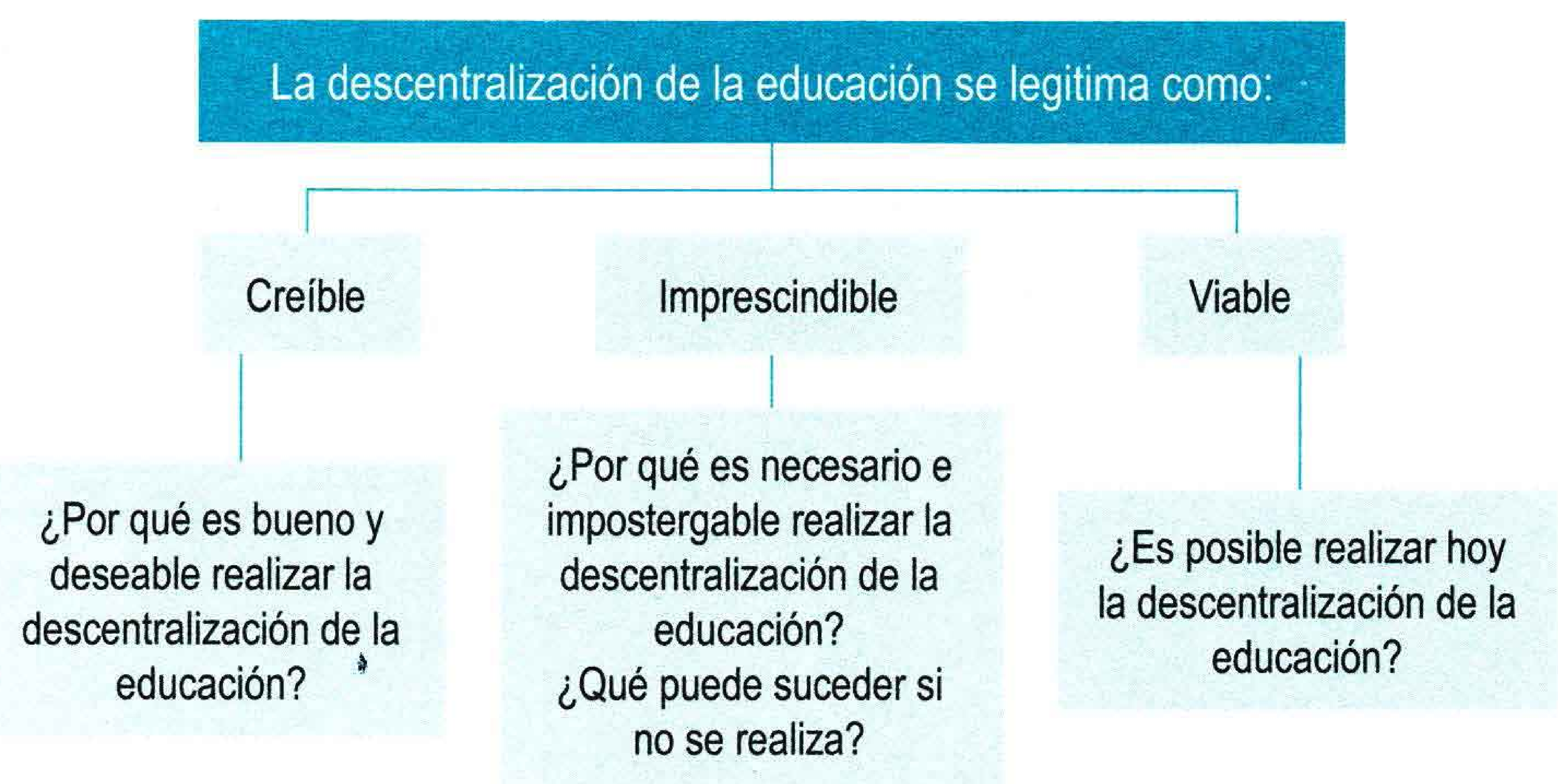

contexto de crisis del Estado -no obstante los posibles entrecruzamientos-, cabe sintetizar algunas tendencias. Según Hevia:

Es posible identificar una racionalidad neoliberal que opera a través de una lógica economicista, cuando las propuestas de descentralización se fundamentan en la necesidad de un ahorro del gasto público, de privatizar la contratación del personal docente o de transferir al sector privado la mayor cantidad de escuelas posibles.

También es posible identificar argumentos en pro de la descentralización, inspirados en una racionalidad geopolítica, cuando se pretende desconcentrar la administración del Estado para lograr una plena ocupación del territorio, promover el desarrollo regional y lograr la integración de las regiones apartadas del conjunto de la nación.
Cercana a esa racionalidad $-\mathrm{y}$ a veces entrelazada con ella- se puede distinguir una lógica de eficiencia administrativa. Se desconcentra para controlar y hacer más eficiente el proceso de toma de decisiones.

Se delega la capacidad de ejecutar, pero sobre la base de criterios previamente establecidos por las autoridades del nivel central.

Es posible distinguir también una lógica de inspiración democrático-participativa, cuya finalidad es otorgar una mayor autonomía de decisión, poder y recursos a las instancias comunales y regionales para resolver los conflictos que se dan en el ámbito educacional. Para la mirada desde el poder local, una administración más cercana a la comunidad permitiría comprometerla para que asuma un mayor control sobre el tipo de formación que se imparte a los estudiantes y pueda, a su vez, aportar al mejoramiento de la calidad educacional de su comuna o región (Hevia 1991, 15-16) 
Dada la influencia del Banco Mundial y del Banco Interamericano de Desarrollo en las denominadas "reformas de mejoramiento de la calidad", es importante recordar que estas fueron acompañadas con un discurso de descentralización. Sin embargo, para los bancos este no fue el criterio central para otorgar préstamos, pues en general sus colocaciones preferenciales han sido dirigidas a los Estados centrales, y para programas centralistas. Sin embargo existieron variantes en algunos países, en los que se dio énfasis a la aplicación del mejoramiento dirigido hacia las escuelas de las regiones y localidades.

\section{Descentralización y cruce de derechos}

Si algo derivamos de las reflexiones anteriores, es que la descentralización educativa debe ser propuesta como un proceso político y pedagógico enfocado a superar las desigualdades y exclusiones ante el saber y la cultura, y a participar en un proceso de desarrollo social y económico que garantice los derechos fundamentales. En la calidad de la educación -directamente condicionada por la calidad de vida, operan múltiples factores. La desigualdad educativa es parte de la desigualdad social. La causa principal para no recibir una educación de calidad es la condición social y económica de pobreza, debilidad de representación y poder político que no permiten superar dicha situación implementando sólidas políticas sociales y económicas.

La educación es un derecho fundamental, está indivisiblemente unida a otros derechos. En esta línea de reflexión, temas como el que nos ocupa de la descentralización educativa, tiene sentido en su vinculación a los problemas básicos del país; es decir, la pobreza, la desigualdad y la exclusión, que no se en- frentan por la carencia de un proyecto político democrático de transformación nacional. De ahí, la pertinencia de la formulación de Cáceres:

En ese marco, la descentralización para ser legítima tiene que desarrollarse como un proceso inclusivo. Lo cual implica que debe desarrollarse modificando relaciones de poder y construyendo sujetos capaces de tomar en sus manos los instrumentos que les permitirán acceder por sí mismos a lo indispensable para una vida digna. Lo cual lleva al tema de la participación ciudadana -de los excluidos- desde una perspectiva de derechos $(2005,12)$

Desde la perspectiva de derechos, se articulan las concepciones sobre el desarrollo, la participación y la promoción de las capacidades de las personas, como las responsabilidades estatales y no estatales. La participación en un desarrollo integral es asumida como un derecho. El derecho a participar en el desarrollo social, económico y cultural mereció una declaración internacional en 1986.

En la línea de la reflexión avanzada, E. Cáceres da una idea concreta para presentar la descentralización:

Desde una óptica de derechos, la descentralización debe ser entendida como un proceso en el que se amplía el ámbito donde se ejercen los derechos de las personas. Lo cual in plica que debe ser vista también como un proceso de identificación y precisión de las obligaciones que generan tales derechos". (Pág. 15) 


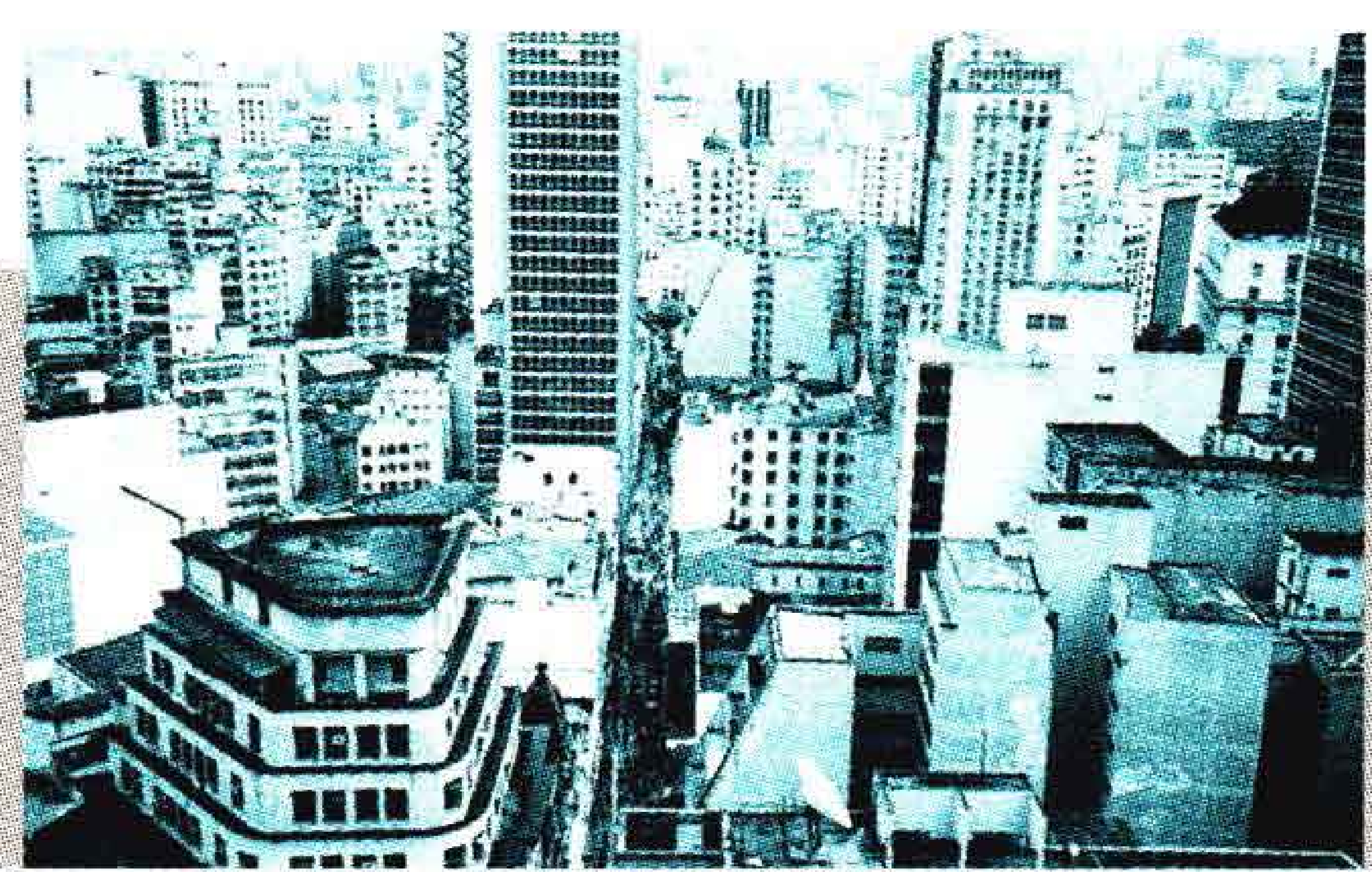

\section{Participación ciudadana}

En una perspectiva democrática participativa, la descentralización educativa significa impulsar un proceso político y pedagógico de ampliación del poder para actores excluidos o relegados en las decisiones -autoridades regionales, comunidad educativa, profesionales calificados, estudiantes-. Dicha descentralización implica la instauración de nuevas competencias y funciones institucionales, como la autonomía de la institución educativa.

Impulsar la descentralización es incorporar a nuevos actores al quehacer público, incluir a los ex- cluidos y, en el caso de los gobiernos regionales, incorporarlos a la política nacional como actores institucionales. El cambio en la descentralización no consiste en la participación de grupos en general, (Mc Gin, 1987, 177) sino en la de determinados grupos bloqueados por poderes dominantes.

La incorporación de los actores en la educación adquiere sentido formando parte de un esfuerzo por aplicar estrategias de desarrollo humano integral, pues el desarrollo favorece la educación y ésta a su vez lo impulsa. En tal desarrollo, la descentralización deberá ser un ámbito favorable para iniciativas que mejoren la calidad y reduzcan las desigualdades en la calidad de la educación.

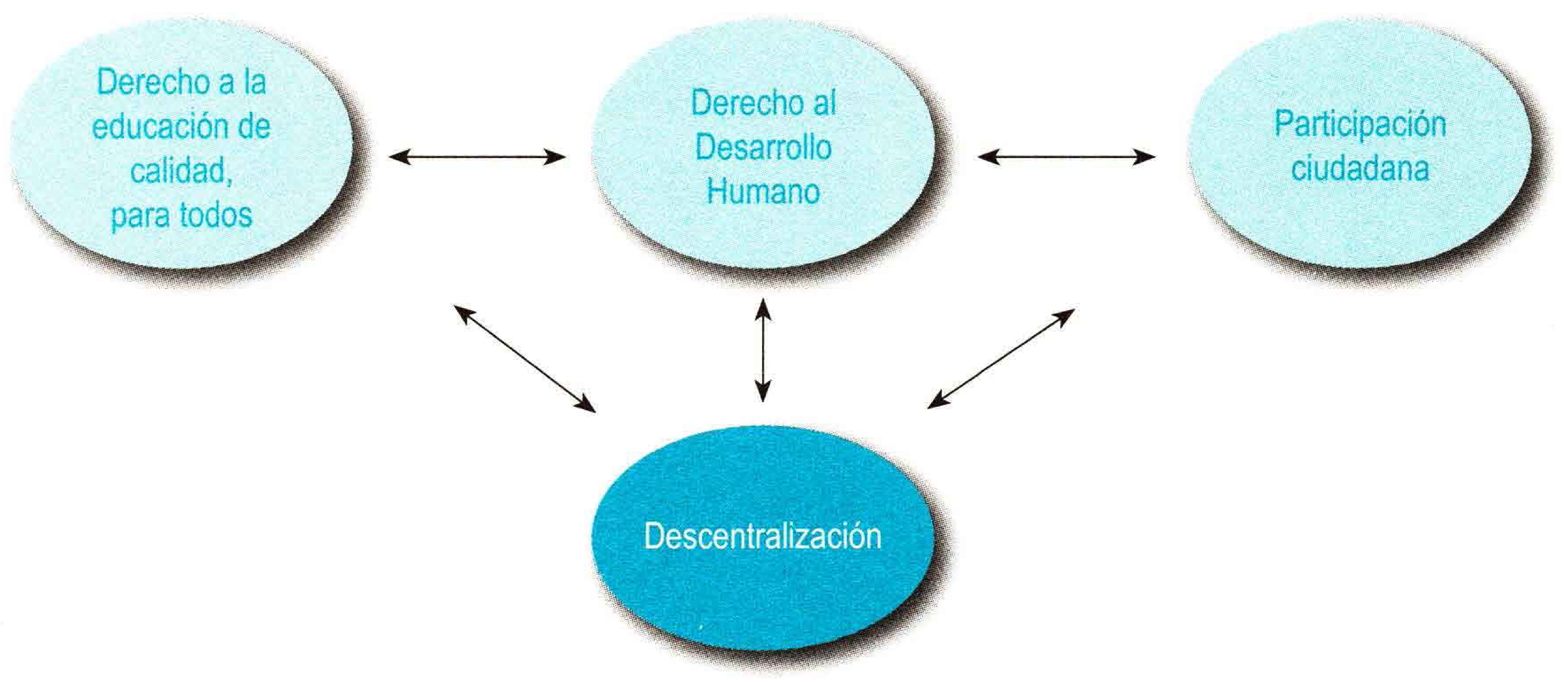


La participación tiene significados sociales, políticos y culturales diversos. La propia perspectiva de derechos "... está inspirada por movimientos autónomos tales como los de las mujeres, los campesinos sin tierra, los pueblos indigenas (...) miriadas de luchas sociales, culturales y políticas tanto del Norte como del Sur" (Eyben, 2003, citado por Cáceres). La participación democrática puede asociarse a la formación de ciudadanos autónomos, además de suponer una metodología o estrategia; pero, "... hablar de la participación en tanto derecho, le otorga algunas caracteristicas al término: valor intrinseco y prioridad, entre otras" (Cáceres, 17).

\section{Preocupación por la desigualdad y la justicia}

Con el avance de los diversos procesos descentralizadores, se confirma la existencia de dificultades y cuestiones críticas que venían siendo esbozadas desde hace varios lustros. Juan Carlos Tedesco (1987), por ejemplo, consideraba que en sociedades con estructuras caracterizadas por fuertes desequilibrios, era poco viable introducir dinamismo y renovación en la esfera de la educación, vía el incentivo de la competencia, pues el sector público y el privado se dirigen a públicos diferentes.

La descentralización también está afectada por las estructuras sociales: "En definitiva, como la disponibilidad de recursos está desigualmente distribui$\mathrm{da}$, la descentralización termina por provocar una mayor correspondencia entre desigualdad social y desigualdad educativa". (Tedesco, 1987, 145). Por ello, la transferencia de responsabilidades requiere un conjunto de condiciones para favorecer mejores resultados educativos.

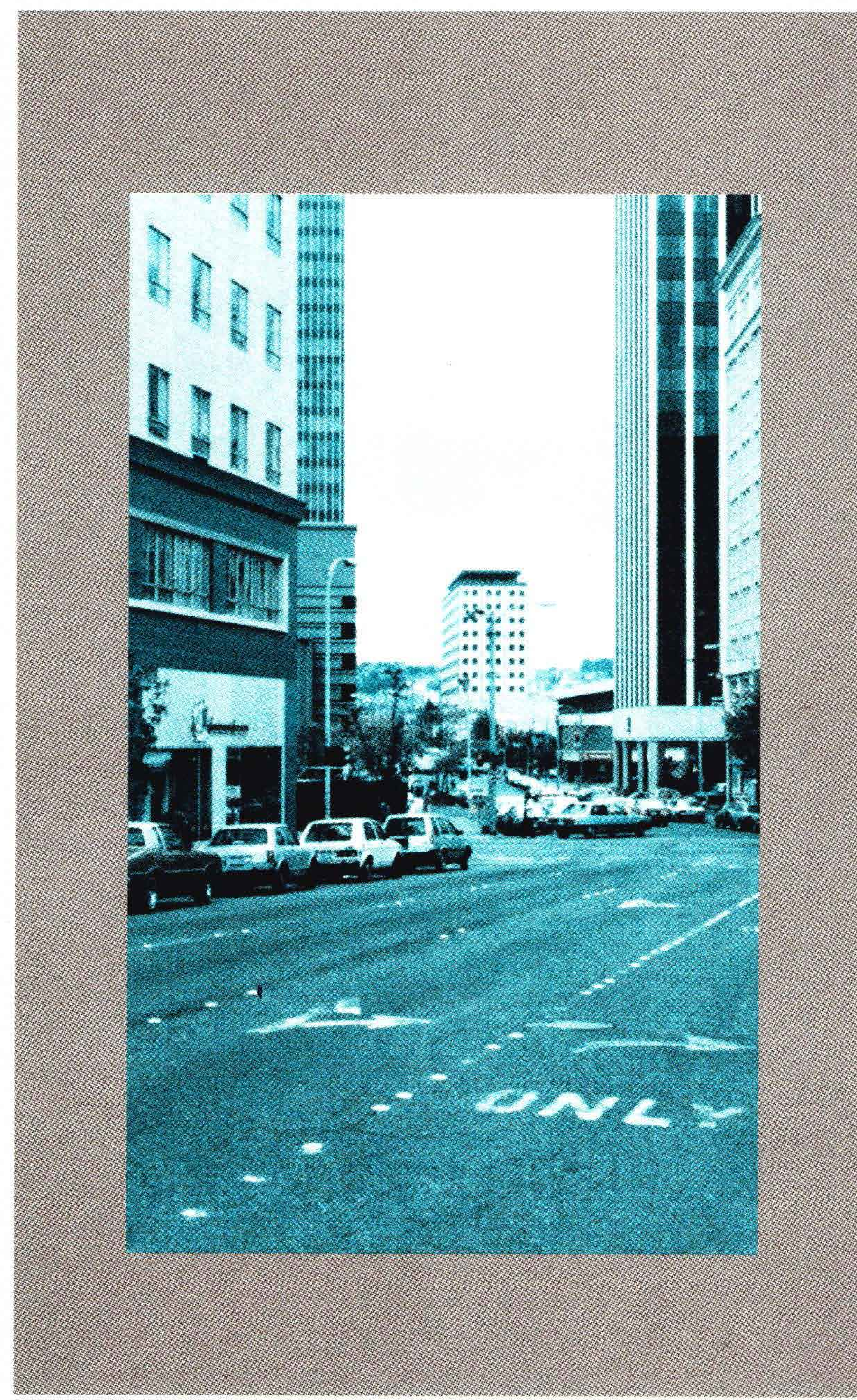


Indica Tedesco, además, que

... el fortalecimiento de la participación, de la capacidad de gestión institucional y, en definitiva, de la responsabilidad por los resultados del trabajo, exige, como condición necesaria, un activo rol de la administración central en la asignación de recursos, de acuerdo con prioridades que superen la capacidad inicial de cada institución, región o ámbito educativo local para desarrollar sus iniciativas. (Tedesco, 1987, 146)

Sin ello, la ampliación de la cobertura se realiza a través de circuitos diferenciados de calidad, que produce una exclusión más sofisticada, consistente en estar dentro de un sistema educativo desigual en lugar de la antigua y directa exclusión para el acceso al sistema. Esta antigua exclusión subsiste también en la imposibilidad de concluir la educación secundaria para un grupo importante de estudiantes. Las opciones de estrategia adquieren, según Tedesco, un valor democrático o antidemocrático se- gún el lugar que ocupen en el conjunto de la política educativa y social.

Estas preocupaciones están expresadas en un pronunciamiento del Foro Educativo, que alerta respecto a que, junto con las medidas de descentralización, resulta de igual importancia asegurar la fuerza de las políticas universales y que ellas contengan mecanismos de compensación de desigualdades en contextos de violencia política; justamente, para no contribuir a agudizarlas.

En este marco, son interesantes las observaciones derivadas de la experiencia regional más reciente. En opinión de Graciela Messina:

La descentralización en América Latina, tuvo lugar en sistemas educativos que se habían expandido aceleradamente desde los años cincuenta, sin resolver el problema de desigualdad y la exclusión. En este marco, si bien la descentralización contiene una promesa de democratización y apertura de los sistemas educativos hacia las culturas locales, no es menos cierto que también ha

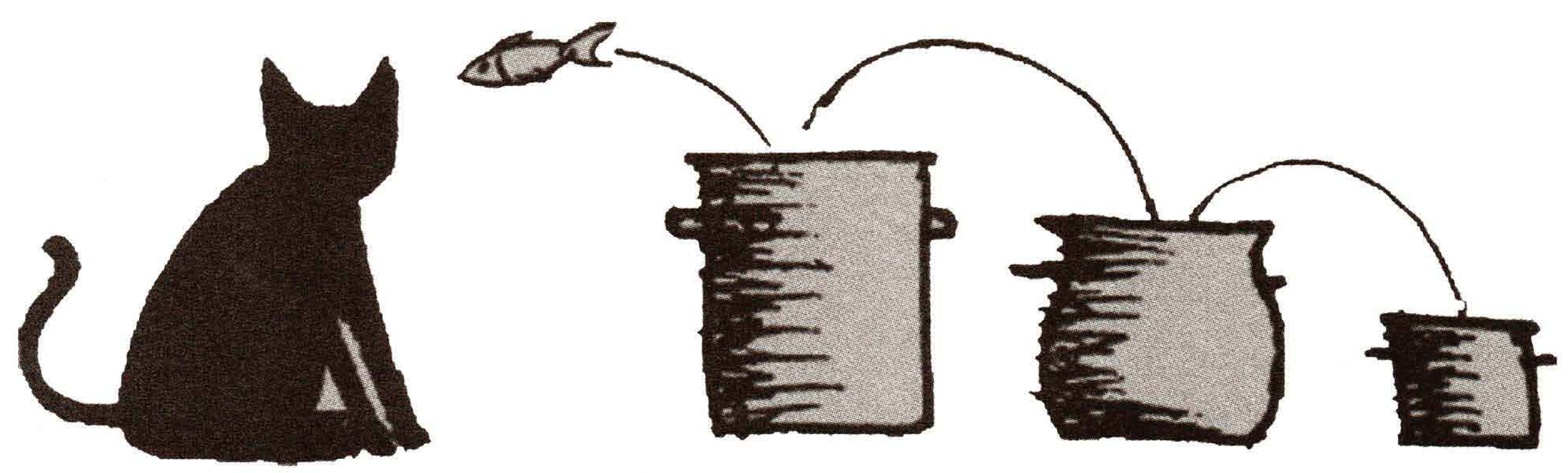




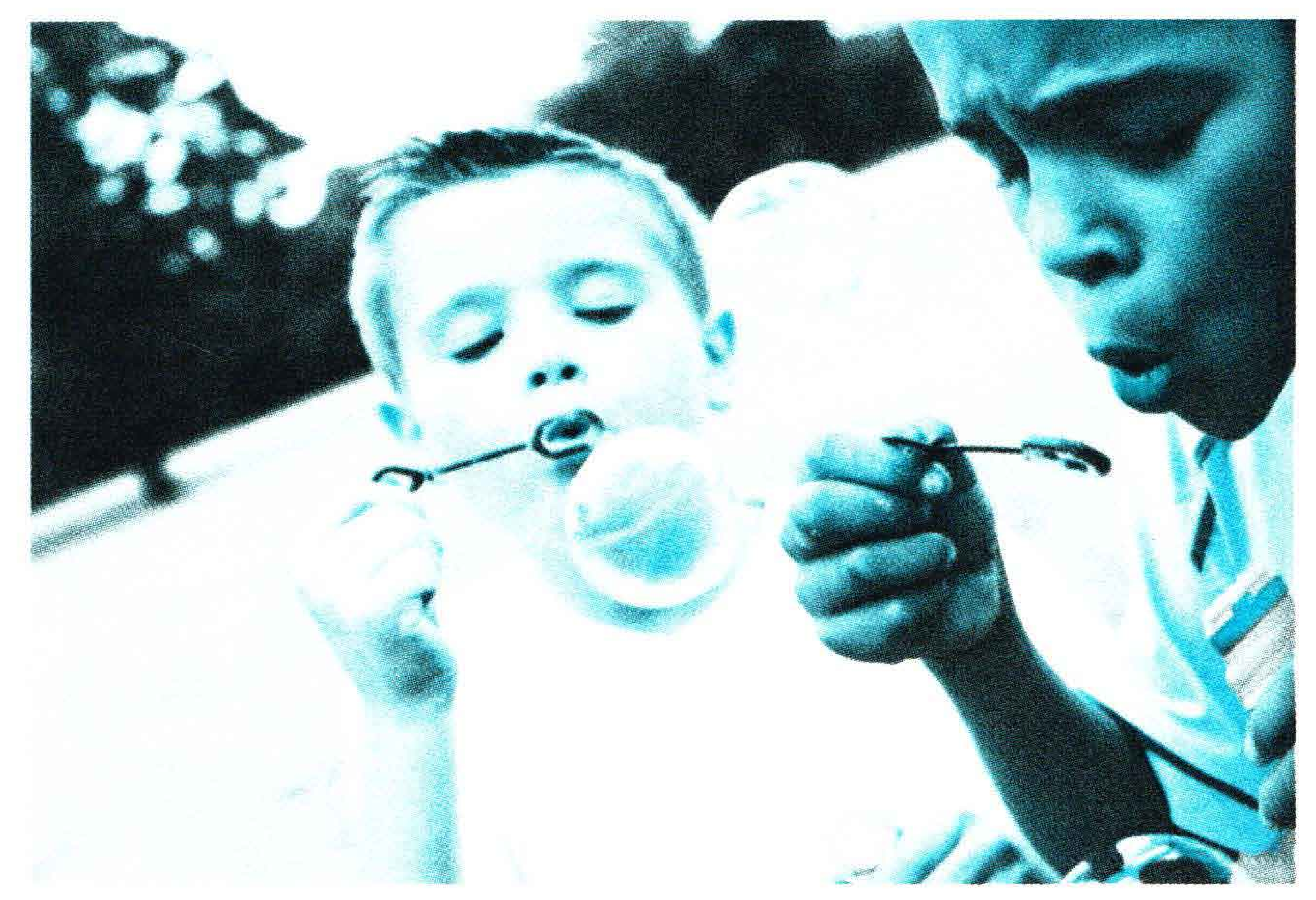

generado nuevas desigualdades en sistemas educativos donde no reinaba la equidad. La descentralización se ha entrecruzado con procesos de recentralización y privatización. En la mayoría de los países no han existido mecanismos al nivel de los escalones centrales e intermedios de los sistemas educativos, para garantizar la descentralización en condiciones de equidad (Messina, 2002, 146-147)

En América Latina, luego de la reforma impulsada durante el gobierno de Augusto Pinochet, reaparece intermitente, aunque en forma débil, la propuesta de implantar un sistema de competencia basado en el subsidio a la demanda, consistente en entregar un monto de dinero por alumno matriculado en la institución educativa. En Perú, también reaparece cada cierto tiempo.
En el caso de Chile, por el subsidio a la demanda se estimula a cada institución para que atraiga estudiantes apelando a mejores ofertas que llevarían a los padres a retirar a sus hijos de otras escuelas. El Estado financia la educación privada directamente o a través del municipio, para que con los voucher por alumno la institución decida su uso -incluido el pago a los docentes-, sobre la base del monto recibido. En esta perspectiva neoliberal, la igualdad de oportunidades no tiene centralidad. Por ello, es bueno recordar ante los procesos de descentralización, la dimensión pública de toda educación y de la educación publica en particular:

Todo proyecto educativo, ya sea que se desarrolle en un modelo de escuela pública, privada o concertada, debe partir de unas aspiraciones mínimas universales que han de ser metas para todos, como son los obje- 


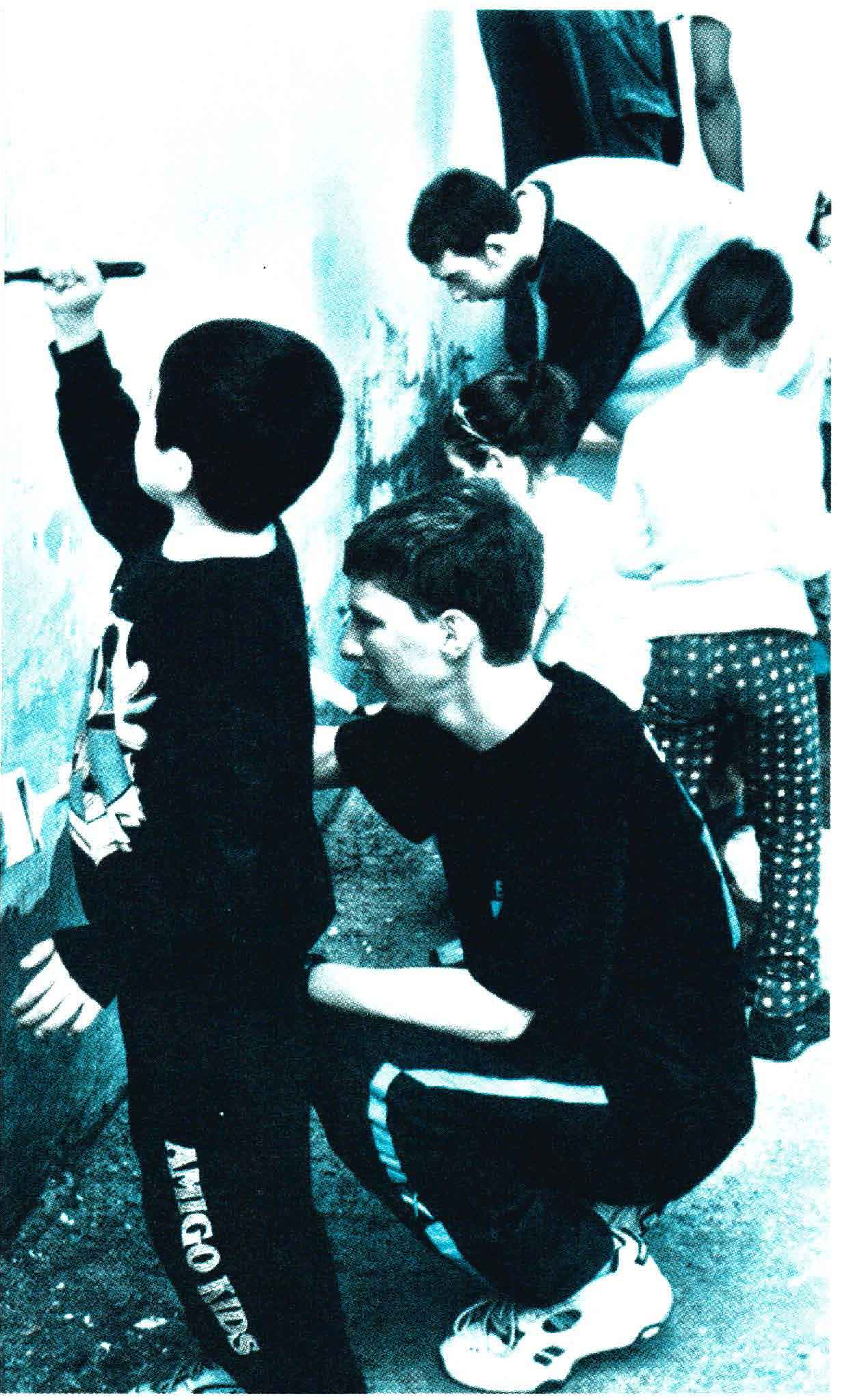

tivos de respetar la dignidad de las personas, que sea de calidad científica y pedagógica o que posibilite y facilite el progreso de todos desde las condiciones desiguales de partida de cada uno. Para que estas aspiraciones sean éticamente defendibles, debemos considerarlas como buenas para todos. La aspiración esencial, específica de la educación pública, es la igualdad para aprovechar el bien que representa la educación; una utopía necesaria (Gimeno, 2001, 42-43)

\section{La descentralización, de cara al desarrollo}

En Perú, por la velocidad con que se reemprendió la descentralización, estamos obligados a pensar en los nuevos significados de la descentralización comenzada en 2003, desde las cuestiones del desarrollo integral, la participación, la globalización y la sociedad del conocimiento. La globalización y la sociedad del conocimiento tienen ya un carácter de "mega tendencia". A decir de Sergio Boisier (2002, 6-7), son causadas o empujadas por otras cuatro fuerzas: la revolución científica y tecnológica, que, mediante la microelectrónica, modifica la producción industrial manufacturera y los sistemas de comunicación y de transporte. La reforma del Estado en América Latina, con las recuperaciones de la democracia formal. Las demandas de autonomía de la sociedad 
civil. Y, por último, las tendencias privatizadoras, que amplían el número de decisores independientes.

Pertinente para la descentralización educativa es que, frente a los enormes desafíos que presentan los territorios, no hay una "... acumulación de prácticas históricas, en parte debido a la rapidez del cambio en la sociedad actual. Esta constatación coloca, en el contexto de la actual sociedad del conocimiento, la cuestión del conocimiento en el cruce de la descentralización y el desarrollo territorial". (Boisier, 2002, 8-9).

Boisier percibe la exigencia de "crear un marco cognitivo nuevo", para investigar "... cómo se articula un territorio con los procesos globales que están en marcha en el mundo -el nuevo entorno- y (...) descubrir las causalidades contemporáneas del crecimiento y del desarrollo -el nuevo interno-". (Boisier, 2002, 8-9). El mismo autor cita a Y. Dror (1996, 123): “... deben hacerse vigorosos esfuerzos para elevar el nivel de entendimiento popular, en relación a temas complejos", a lo que agrega Boisier que "... no hay tema social más complejo e importante que el propio desarrollo". Así mismo, cita a J. Stiglitz (2000, 130) cuando señala que "... el éxito de una economía basada en el conocimiento, también requerirá una ciudadania altamente educada, con fuertes habilidades cognitivas, y una efectiva red descentralizada de comunicaciones". Concluye Boisier, a partir de estas citas, que ambos autores expresan la necesidad de lograr "... cambios en los modelos mentales de los 'operadores del desarrollo', desde los agentes sociales de base, hasta las más altas autoridades politicas, y ello apunta a un 'saber' actualizado". (Boisier, 2002, 13).

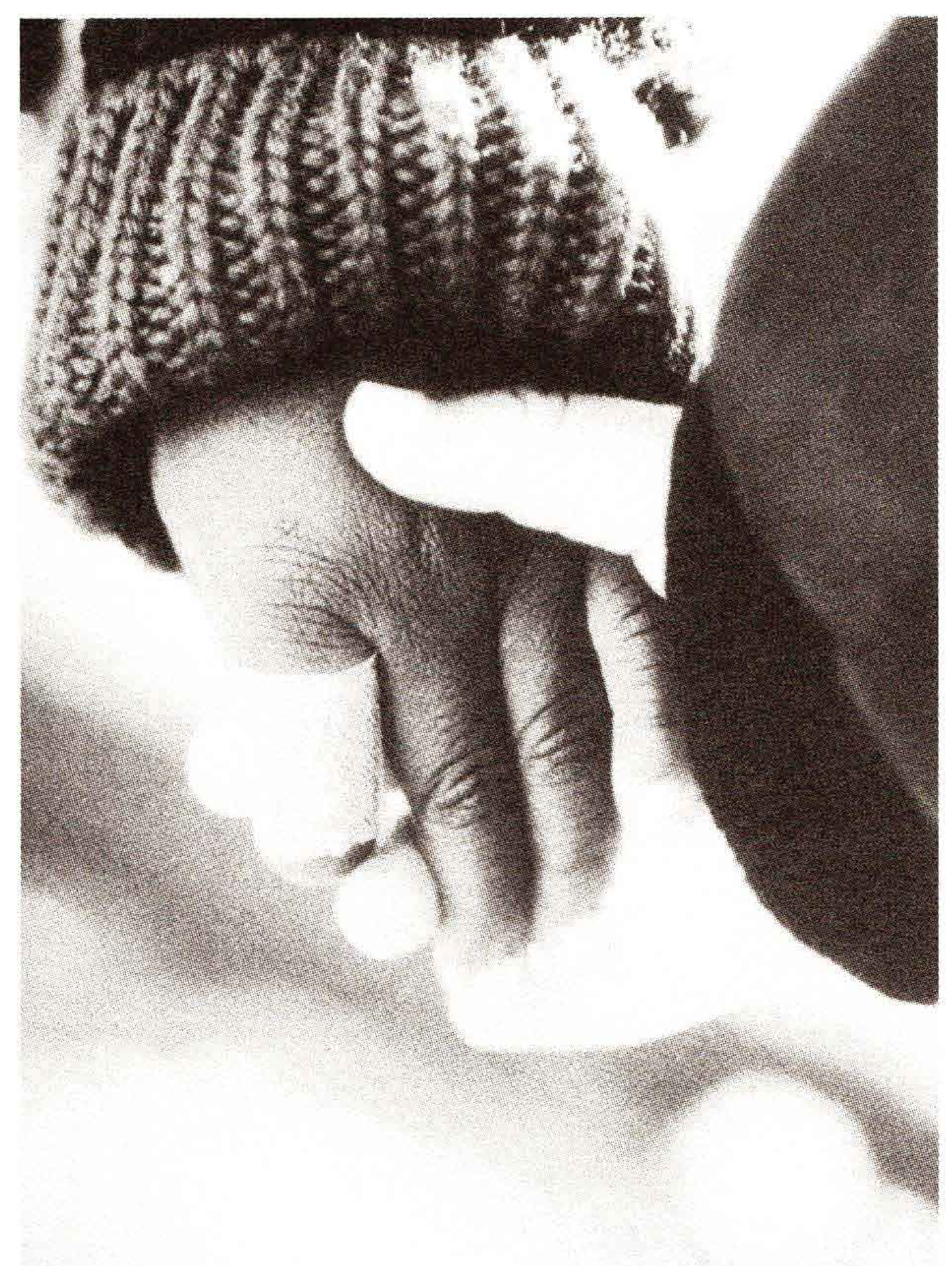

\section{Diversidad en el diseño institucional en América Latina}

Como hemos referido, la descentralización, extendida durante los últimos lustros del siglo pasado, tiene diversas formas. La transferencia del gobierno y la gestión de las escuelas desde el Estado central a los niveles subnacionales, se muestra en algunos grandes tipos. Así, las repúblicas federales del continente -casos de México, Venezuela y Argentina- ya transfirieron las escuelas a sus Es- 
tados. En Brasil, hay una distribución de la educación escolar entre la Unión, los Estados y los municipios. En las repúblicas unitarias -como Colombia, Chile y Bolivia- las municipalidades tienen mayor implicación en la gestión; en particular en la provisión del servicio y en la participación social, y menos en el financiamiento, el currículo y la política docente.

Durante la segunda mitad de la década pasada varios países de América del Sur aplicaron políticas de transferencia de competencias"de gestión o continuaron las iniciadas años atrás. La tendencia general se registra en un estudio realizado por el Banco Interamericano de Desarrollo.

Es preciso hacer intercambios dirigidos a un balance del proceso en la Región Andina. Como dijimos, en varios países la definición relativamente orgánica de la descentralización educativa es parte de mayores o menores pasos de descentralización global de los Estados, y de cambios políticos de pretensión más amplia, como el enfrentamiento a las crisis de legitimidad de los Estados, en casos como la transición de régimen político en Perú, luego del año 2000.

Se han producido varias olas de descentralización, con casos nacionales de claro conflicto, negociaciones y estancamiento, y reversión en algunos aspectos. Encontramos, pues, superposiciones de estructuras, con origen en racionalidades distintas, al sucederse gobiernos de tendencia política diferente.

Los temas son la dirección de los sistemas, ubicación de las competencias, la participación social, el financiamiento, para favorecer la comparación y

\section{Cuadro 1}

\section{Nivel de Gobierno formalmente responsable por la provisión de educación primaria}

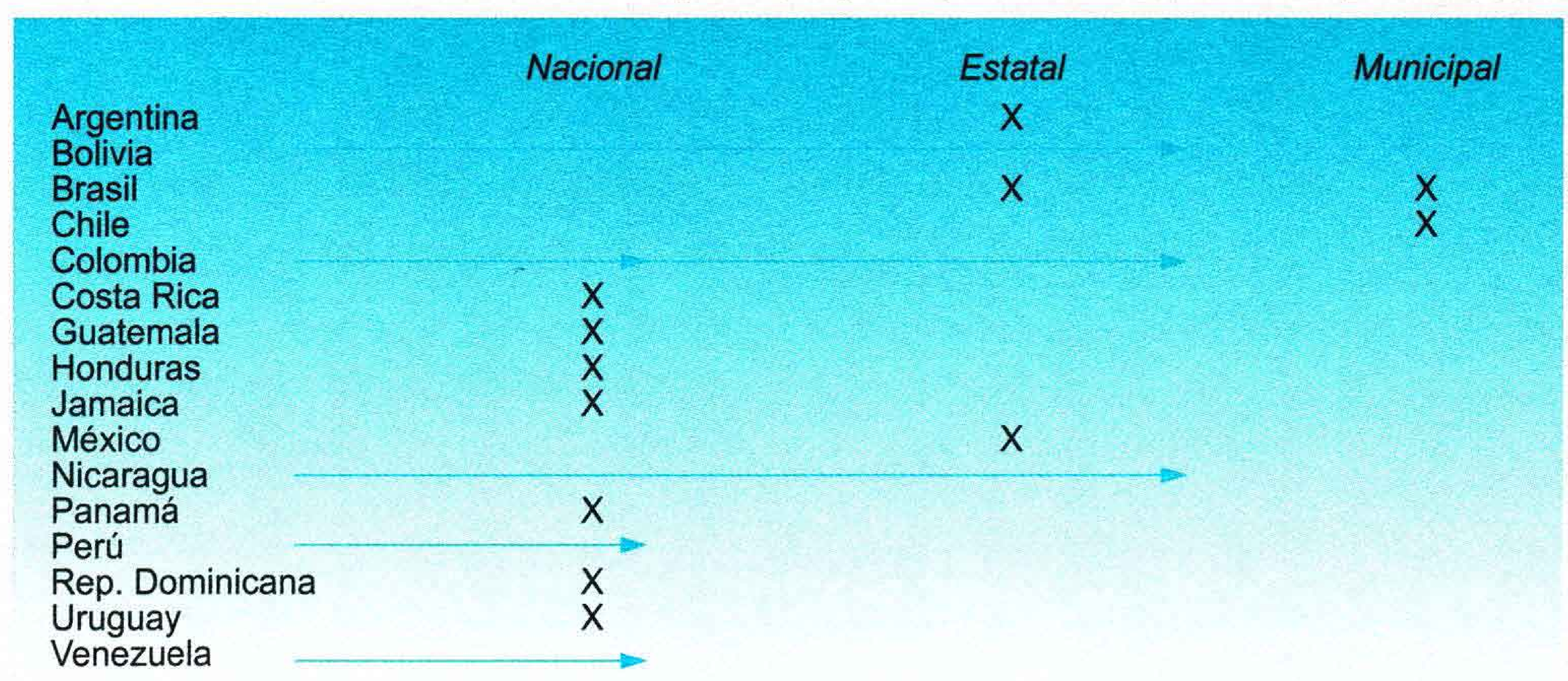

Nota: las " $X$ " indican que las principales funciones son responsabilidad de este nivel de gobierno, incluyendo el empleo, gerencia, inversiones y mantenimiento. Las flechas indican que un proceso de descentralización está en progreso. En los casos donde la responsabilidad está a nivel estatal o municipal, el gobierno nacional retiene algunas funciones en la provisión de los servicios, tales como programas compensatorios.

Los gastos corrientes pasan a los departamentos mientras que los recursos de inversión se transfieren a las municipalidades.

Fuentes: varias publicaciones y entrevistas

Tomado de: Cómo organizar con éxito los servicios sociales. BID, 1997, p. 71. 


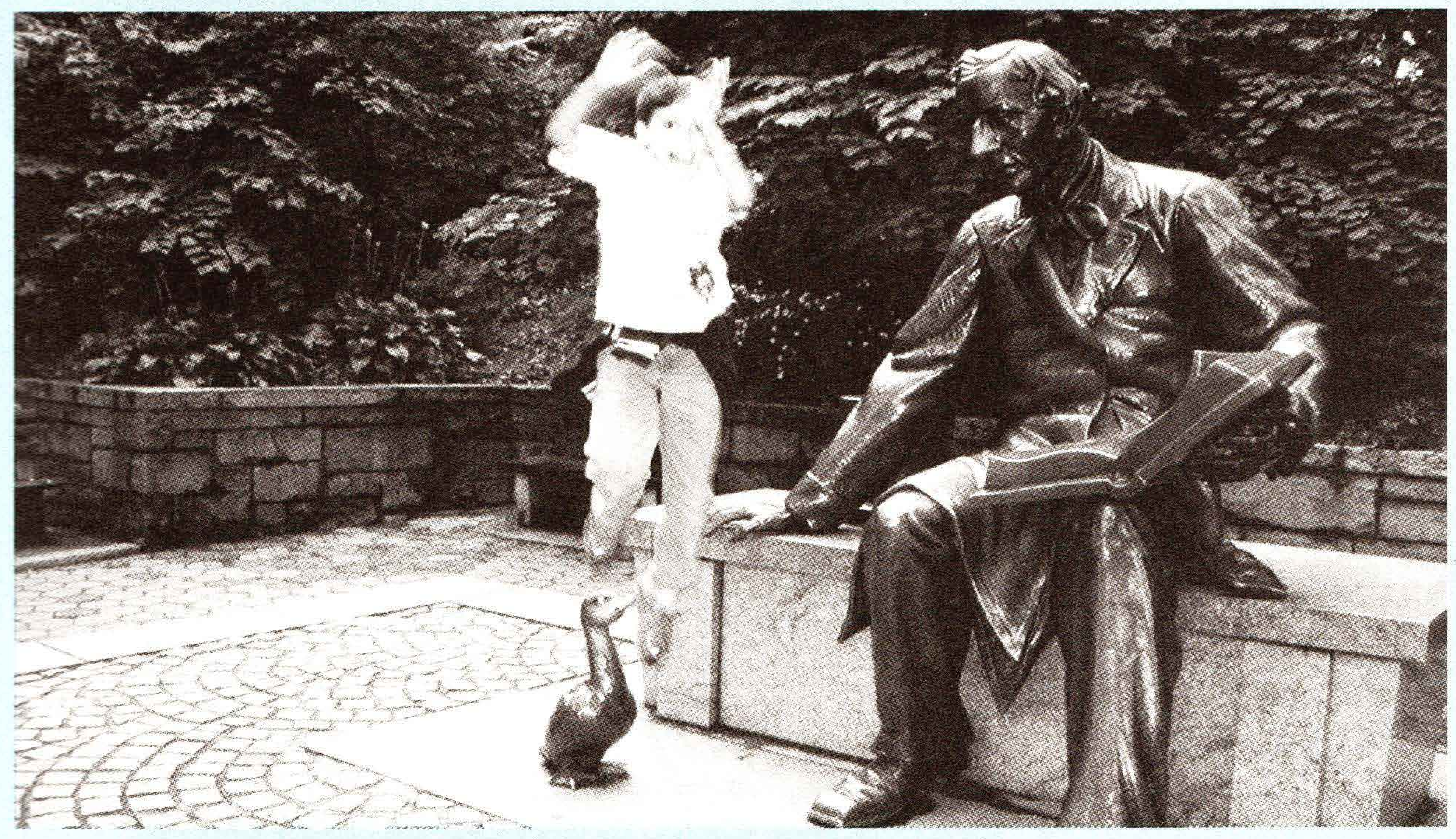

el análisis critico del proceso. Los procesos pedagógicos merecen un tratamiento especial.

En Perú y otros países, las leyes que afianzaron el proceso de descentralización educativa tienen una clara afirmación de la educación como derecho fundamental. En Colombia, ese derecho se afirma en la Constitución de 1991 y en la Ley General de Educación 115 del año 1994 -que no cierran la posibilidad de aranceles en el sector estatal-. En Bolivia, con la Ley de Reforma Educativa, LRE, promulgada en julio de 1994. Y la Ley General de Educación del Perú (2003), que recupera el concepto de derecho fundamental evitado en la Constitución de Fujimori, así como afirma con más claridad el derecho a la gratuidad, cuando la imparte el Estado.

\section{Perfil de los gobiernos nacionales}

La descentralización, a pesar de la aspiración de algunos desus impulsores, como los bancos de financiamiento, con una retórica de descentralización poco real, fue requiriendo un Estado central conductor, regulador y activo en programas y proyectos educativos; pero éste fue debilitado estructuralmente en su planificación, con la privatizaron desbocada, la subordinación en las políticas y la desprofesionalización de la administración pública. Ese Estado es el que ahora fracasa, para amortiguar las desigualdades extremas en materia educativa. 


\section{Me}

La concreción de la transferencia y, luego, la continuidad del sistema con algunas competencias trasladadas a los niveles sub-nacionales algo más autónomos en sus competencias- hicieron necesario un Ministerio más calificado para políticas de control y regulación; calificación poco lograda, en general.

En educación, es claro que ningún nivel de gestión maneja todos los factores de calidad y equidad. Esa mira de la calidad implica que el esfuerzo del Estado y la sociedad debe conjugarse con la descentralización para lograr un esquema no de menos Estado, sino de mejor Estado. Es pertinente recordar que la descentralización y la centralización coexisten siempre; no hay un sistema político puramente centralista o puramente descentralista, si bien los regímenes políticos enfatizan una $u$ otra forma de distribución del poder. Por ello, es errado afirmar que, luego de las transferencias de los programas sociales, el desarrollo local es responsabilidad de "las localidades" y no una materia que incumba al conjunto del país y al Estado nacional.

En educación, el Ministerio adquiere una mayor capacidad de iniciativa, de modo selectivo, a través de la posibilidad de impulsar reformas con apoyo financiero internacional, como la provisión de importantes insumos -texto escolar, bibliotecas de aula, capacitación de docentes en ejercicio-, las evaluaciones nacionales y el planteamiento de nuevas propuestas curriculares.

En el caso de Perú, la descentralización se reinició cuando el Ministerio de Educación ya venía ampliando sus campos de intervención en los llamados "programas nacionales" o, luego, "estratégicos", como los de Huascarán -nuevas tecnologías, alfabetización y educación rural-. Como se ha dicho, los Estados en proceso de descentralización inventan formas de mantener vínculos con las instituciones educativas.

El problema se produce cuando es casi nula su capacidad de universalizar un servicio de calidad y equidad; por ello, son débiles para enfrentar las desigualdades; sus programas no promueven el desarrollo de capacidades locales e institucionales. Los programas de mejoramiento de la calidad, promovidos por los bancos de financiamiento, no han incluido la orientación hacia la descentralización sino una mayor iniciativa sólo del nivel central y de organizaciones privadas.

La tendencia a resumir la descentralización en la autonomía escolar y a subvalorar el papel del Ministerio de Educación y del sistema educativo adquirió mucha fuerza. Nos parece que el tema es de vieja data. Así opina Luis E. Valcárcel, indigenista destacado, quien fuera Ministro de Educación de Colombia entre 1945 y 1947. Él quería transformar el Ministerio "... de organismo administrador de centros escolares, a agente impulsor del desarrollo cultural".

Bien merece transcribir la noción de sistema educativo y su sentido, de J. Gimeno:

Puesto que se ha hecho de este sistema el instrumento por antonomasia para dar cumplimiento al derecho de todos a la educación, debe ordenarse de modo que los ciudadanos y ciudadanas tengan garan-

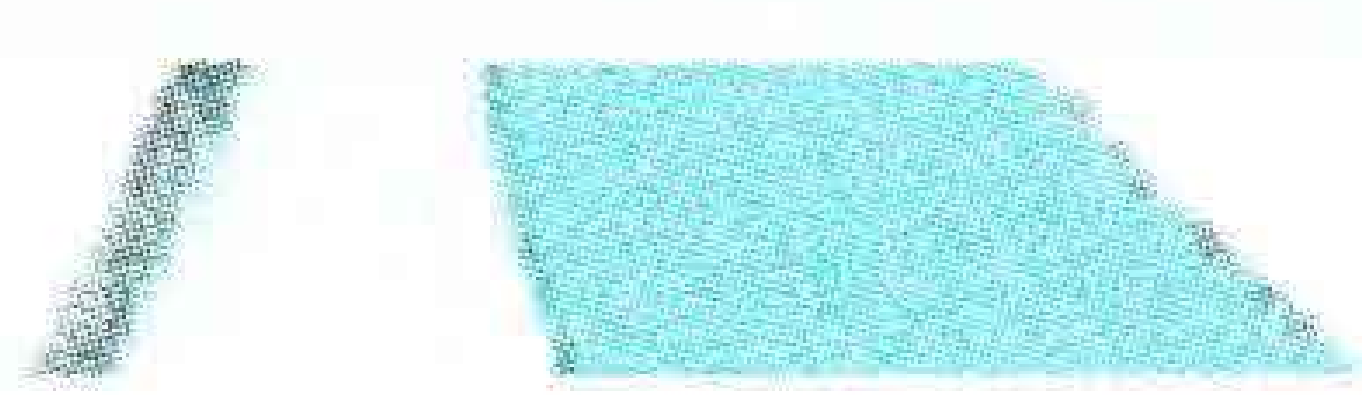


tía de que ese derecho les será asegurado, y de que, en un Estado democrático, lo podrán disfrutar en igualdad de oportunidades, en el marco del territorio y de la población que compone al Estado, que es la instancia política y jurídica que garantiza el derecho de las personas. El sistema escolar representa también una esfera importante en la cual desarrollar y ejercer el principio de solidaridad, a través de la distribución de recursos. (...) Se espera que satisfaga fines comunes (...). La lógica de la existencia del sistema como tal, implica y necesita, pues, que actúe de manera ordenada en una dirección y no en otras, que se obligue a subordinar algunos intereses de grupos y de personas a lo que tiene valor para todos, a no poder satisfacer libertades ilimitadas de unos en detrimento de las de otros $(2005,88)$.

Entre los problemas de la experiencia descentralizadora, resalta la reproducción del centralismo en los niveles subnacionales y la ausencia de funcionarios calificados. En relación con esto, se espera la dinamización de los mecanismos propios de una carrera administrativa pública.

\section{La dimensión pedagógica: desigualdad, diversidad, estándares}

En términos de calidad de la educación, parte de la idea que descentralización es el impulso a una mayor diversidad educativa, integrando contenidos de las culturas locales y favoreciendo su enriquecimiento. En este sentido, descentralizar es además una aspiración antigua en el pensamiento educativo, como lo es la idea de que el proceso formativo se produce también en ámbitos diferentes a la escuela, durante toda la vida. La noción de sociedad educadora, retomada por ejemplo en la Ley General de Educación peruana, es un enfoque que beneficia a la descentralización. En términos de la reflexión pedagógica, la descentralización debe permitir una mayor fluidez en el diálogo entre los saberes escolares y otros aprendizajes, en los diferentes ámbitos sociales y facilitar una mayor y mejor comunicación entre ciudadanos diferentes.

Para el proceso de descentralización pedagógica -en el caso boliviano y también en el peruano- ahora está más presente la propuesta de "interculturalidad", incorporada a su legislación como rasgo del conjunto de la educación. Desde este concepto, podemos esperar un mejor debate con dos polos: uno, las propuestas de modernización con actores sin arraigo, y, a la vez, 
otras con afirmaciones populistas que sostienen que en las culturas populares locales se encuentran los elementos suficientes para su desarrollo y su emancipación.

En América Latina la mirada pedagógica tuvo poca importancia en varios procesos de descentralización educativa; hubo, más bien, un énfasis en la racionalidad financiera y fiscal. Además, éstos se dieron con una casi nula participación de los docentes en su condición de portadores de un saber propio. Durante la década de los noventa, la cuestión pedagógica ingresó con fuerza al aplicarse las mediciones de rendimiento en algunos aprendizajes importantes, como comunicación, razonamiento matemático y equidad.
En los últimos años han seguido aumentando los países que realizan pruebas nacionales estandarizadas. Es una política diferente a la de la diversidad. ¿Es incompatible? ¿Es complementaria? Ambas orientaciones se sustentan en la equidad. Varios países de América Latina participan en pruebas internacionales, como la PISA. Todas han resaltado la desigualdad de aprendizajes entre los países y, al interior de ellos, su estrecha relación con las características socioeconómicas de los estudiantes.

Para desarrollar una discusión de fondo sobre las cuestiones actuales del aprendizaje y la enseñanza, se debe también incluir el hecho de que la mayor iniciativa en cuestiones curriculares y programas na-

\section{Cuadro 2}

Exámenes de evaluación del sistema educativo, en los ciclos primario y secundario

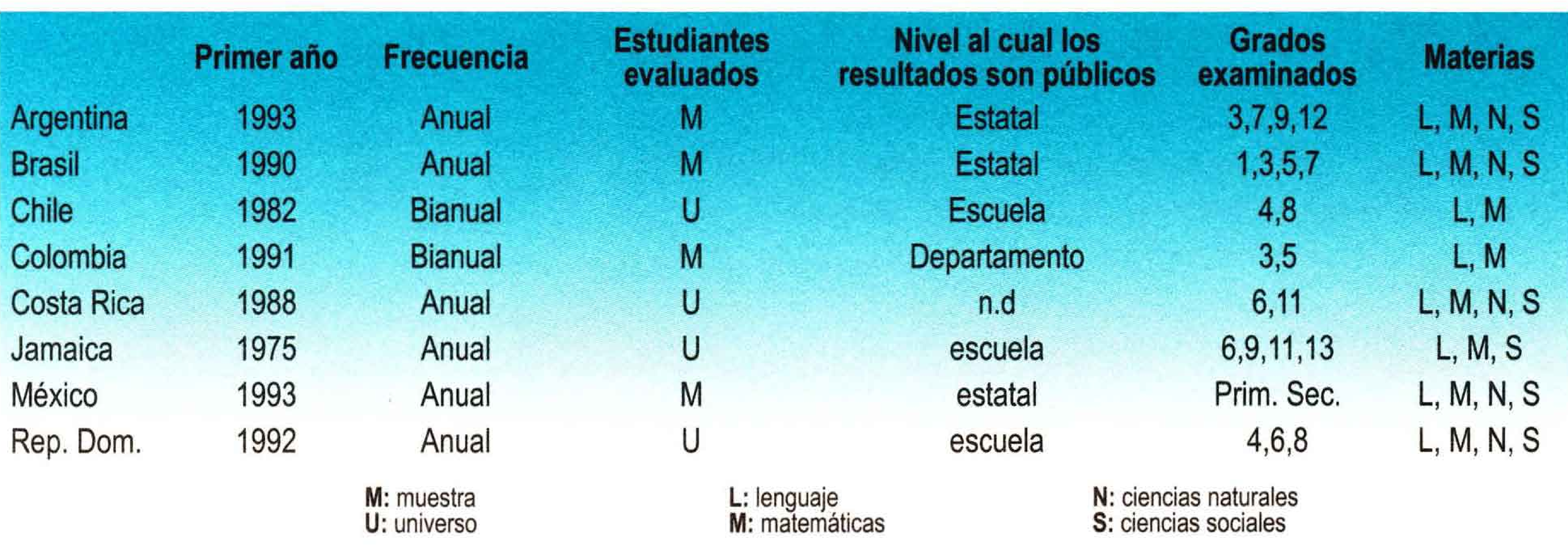

a) Minas Gerais, en Brasil, comenzó un sistema paralelo en 1992 para monitorear el aprendizaje estudiantil. El universo de estudiantes es evaluado y los resultados son enviados a cada escuela.

b) Los exámenes en la República Dominicana son utilizados simultáneamente como mecanismos de evaluación del estudiante.

Fuentes: varias publicaciones y entrevistas.

Tomado de: BID, Cómo organizar con éxito los servicios sociales. 


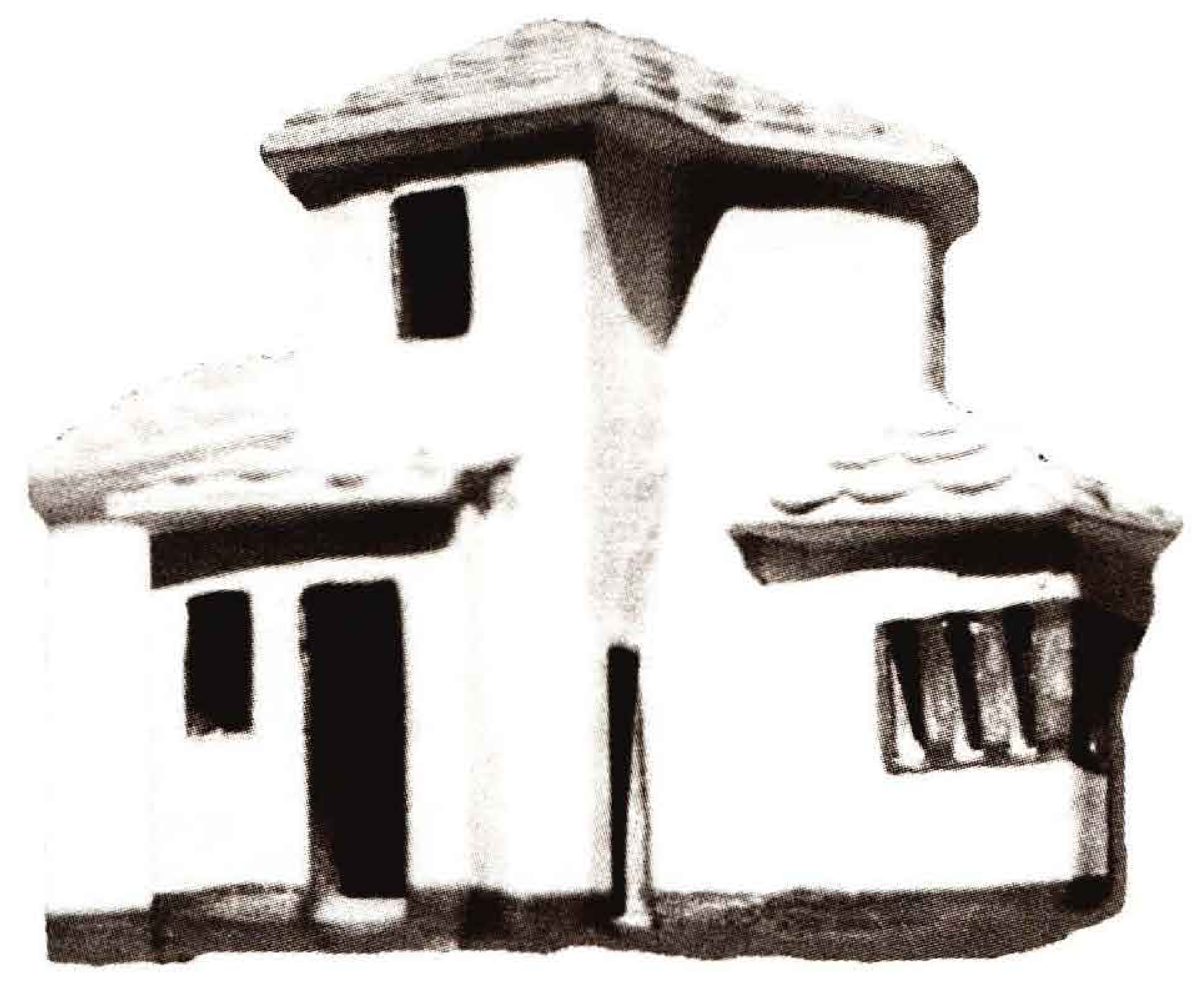

vos de fondo para secto-

cionales de mejoramiento ha estado en muchos casos ligada al financiamiento de la banca internacional, que amplió su presencia en el sector de la educación en muchos países del Tercer Mundo, con un mismo patrón de reforma educativa impuesto, matizado en los países sólo por los ministerios de educación.

Una importante expresión de poder central está en la regulación pedagógica que expresan las mediciones nacionales de rendimiento. $\mathrm{Al}$ inicio de la década pasada se tenía el siguiente listado:

Desde mediados de la década pasada Perú también viene realizando mediciones nacionales. La cuarta (2004), cuyos resultados acaban de ser presentados, revela nuevamente bajos resultados de aprendizaje, y no se ve mejoramiento en comparación con la medición del año 2001.

Entonces, hoy lo más destacado sigue siendo los niveles bajos de aprendizaje en el sector público y parte del sector privado; así como las enormes desigualdades, si se compara el área rural con la urbana y el número de estudiantes no-pobres, pobres y pobres extremos.

Se replantea con más fuerza, desde los rendimientos, la imposibilidad de mejoramientos educati- res masivos sin realizar políticas que generen bienestar y mayor equidad social a las familias, desde la economía y las políticas sociales.

También se evidencia que la mayor y más clara fuerza de presión por el cambio de la educación tiene sentido. Estas mediciones permiten la denuncia de la desigualdad educativa y su rol de reproducción de la desigualdad social; y, a la vez, nos hacen concientes de que sin vigorosas politicas nacionales de mejora, sin crear condiciones de aprendizaje, sin análisis suficiente de la diversidad, y con la pretensión de que en el corto plazo se deben alcanzar las mismas metas a nivel nacional, las mediciones de rendimiento se pueden usar para desprestigiar la escuela pública. Pero el desafío sigue ahí: es legitimar con resultados de equidad la escuela pública, o aceptar que se impondrá su debilitamiento y las políticas de subsidio a la demanda.

Las buenas prácticas existentes, en general, pueden desarrollase con los apoyos específicos que tienen fuera de los ministerios de educación; pero su expansión y sostenimiento requieren de otras políticas nacionales, regionales y locales. 


\section{Bibliografía}

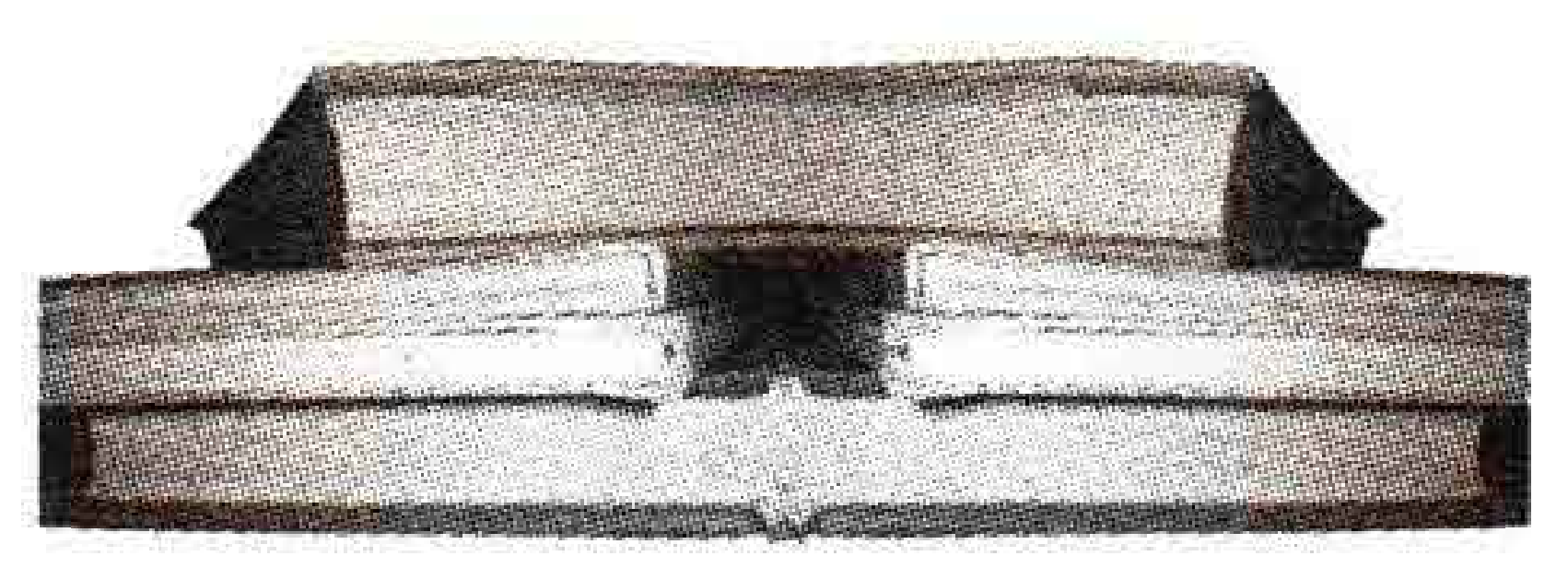

Banco Interamericano de Desarrollo, BID. Cómo organizar con éxito los servicios sociales, Santiago de Chile, 1997.

Boisier, Sergio. "2001: la odisea dẹl desarrollo territorial en América Latina. La búsqueda del desarrollo territorial y la descentralización”. Seminario "Descentralización de Sectores Sociales: nudos críticos y alternativas", Lima, MIPRE y MINSA, 2002.

Cáceres, Eduardo. “¿Nuevas relaciones? Estado y ciudadanos en el contexto de la descentralización", en: "La democratización de la gestión educativa, Mesa de Agencias Bilaterales de Cooperación en Educación", Lima, 2005.

Cuenca, Ricardo. "La democratización de la gestión educativa", Introducción, Mesa de Agencias Bilaterales de Cooperación en Educación, Lima, 2005.

Foro Educativo "Descentralizar para mejorar", Pronunciamiento, Lima, octubre de 1999.

"¿Qué se puede ganar descentralizando la educación?, ¿es posible diferenciarse sin desigualdad?", en: Gairín J. (coordinador). La descentralización educativa: ¿una solución o un problema?, Madrid, Praxis, 2005.

Gimeno S., José. "La enseñanza y educación públicas. Los retos de responder a la obligación de la igualdad, respetar la diversidad y ofrecer calidad", en: Gimeno S., José (coordinador), Los retos de la enseñanza pública, Madrid, Akal, 2001.
Hevia, Ricardo. Política de descentralización en la educación básica y media en América Latina, Santiago, UNESCO-Reduc., 1991.

Iguiñiz, Manuel. "La descentralización y la transformación en educación”, revista Tarea, No 61, Lima, agosto de 2005.

"La transición democrática y los acuerdos de educación en el Perú", en Revista Iberoamericana de Educación, № 34, Madrid, OEI, enero-abril de 2004.

Mc Gin, Noel. "Un proyecto de investigaciones y acción para la descentralización de sistemas educacionales en América Latina y el Caribe". La Educación, No. 101, Washington, OEA, 1991.

Messina, Graciela. "Capacitación en tiempos de descentralización", en: "Seminario Internacional Formación continua de docentes en servicio", Lima, Ministerio de Educación, GTZ, KFW, 2002.

Rivero, José. "Educación y exclusión en América Latina", Lima, en: revista Tarea, 2000.

Senén, Silvia. "Una nueva agenda para la descentralización educativa", en: Revista Iberoamericana de Educación, No. 4, Madrid, OEI, enero-abril de 1994.

Sime, Luis. "El eco de las voces. Perspectivas para el análisis de los discursos educativos", en: Educación, revista del Departamento de Educación, Vol. IV, No. 8, Lima, PUC, 1995.

Tedesco, Juan Carlos. El desafio educativo, Buenos Aires, Grupo Editor Latinoamericano, 1987. 